reinforce the interest of an initial peritoneal staging in order not to ignore an advanced tumor stage.

\section{EN-BLOCK CYTOREDUCTION FOR ADVANCED OVARIAN CANCER}

I Biliatis*, V Mitsopoulos. Poole Hospital, UK

\subsection{6/ijgc-2021-ESG0.520}

Introduction/Background* Surgical procedures in primary debulking operations are challenging. Teaching these procedures in young Gynae/Oncologist aslo poses significant difficulties. En-block systematic excision of specimens could possibly lead to better undersatnding of peritoneal anatomy and facilitate training.

Methodology Primary debulking for advanced ovarian cancer in a 64 year old patient with stage 3C high grade serous ovarian cancer. The operation was performed in a systematic way allowing for excision of the spleen, omentum, right diaphragmatic peritoneum, Morrison's pouch peritoneum, lateral abdominal peritoneum, uterus, ovaries, tubes, rectosigmoid colectomy and pelvic peritoneum in one single specimen.

Result(s)* Complete cytoreduction was acheived with minimal blood loss. The patient went home on post op day 7

Conclusion* En-block excision of specimens in advanced ovarian cancer might be a good method of training young Gynae/ Oncologist in performing primary debulking operations for advanced ovarian cancer

\section{DEBULKING SURGERY FOR TREATMENT ADVANCED- STAGE OVARIAN CANCER WITH HIPEC COMPARED WITH DEBULKING SURGERY WITHOUT HIPEC, SHORT- TERM OUTCOMES}

N Tarasov*, R Faiskhanova, A Fatikhova, R Bainazarov, E Gantseva, V Pushkarev. Republican Oncology Dispensary, Gynecological oncology department, Ufa, Russian Federation

\subsection{6/ijgc-2021-ESG0.521}

Introduction/Background* The gold standart of advanced-stage ovarian cancer treatment is debulking surgery and systematic chemotherapy. However, alternative ways of drug delivery are exist and Hyperthermic Intraperitoneal Chemotherapy (HIPEC) is one of such methods.

Since June 2020 we have started to perform these procedures In Republican Oncology Clinic, Ufa, Russian Federation for the purpose of upgrade the medical care for women with advanced-stage ovarian cancer.

Methodology

Result(s)* Eighteen cytoreduction procedures were made from June 2020 through May 2021 and HIPEC was considered at the time of debulking surgery in six cases. There were four patients with stage $3 \mathrm{~B}$ and fourteen with 3C. The mean time of procedure was 570 minutes in debulking surgery plus HIPEC group and 387 minutes in the group of debulking surgery only. The median postoperative hospital stay was 25 days in the group with HIPEC and 11 days in the group without HIPEC. It was performed 12 optimal debulking procedures with the completeness of cytoreduction score (CC) -1 , and 6 complete debulking procedures CC -0 . The average score of

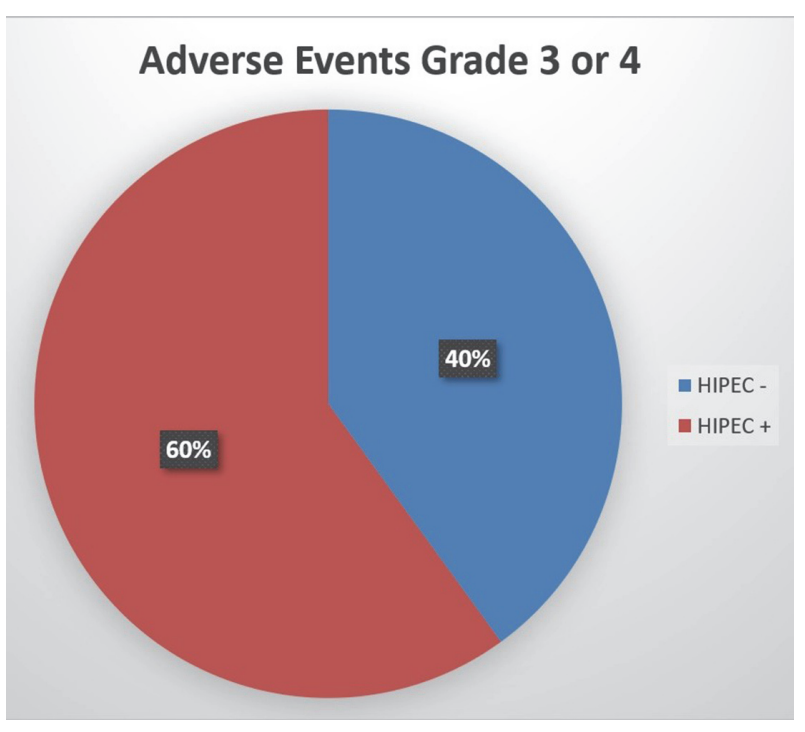

Abstract 1171 Figure 1

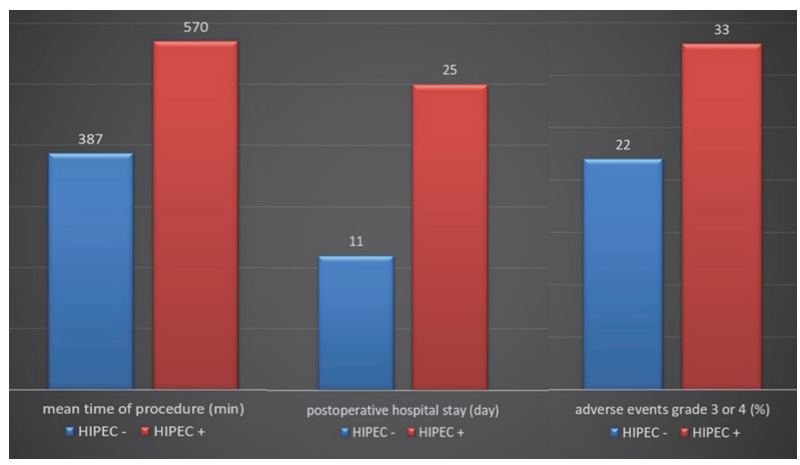

Abstract 1171 Figure 2

peritoneal carcinomatosis index was 15,6 . The percentage of patients who had adverse events of grade 3 or 4 in surgery with HIPEC group was 33\%, and in surgery group - 22\%. Out of $100 \%$ adverse events of grade 3 or 4, 60\% complications were in the surgery with HIPEC group.

Conclusion* Overall, our data shows that addition HIPEC to the debulking procedure extends mean time of procedure, postoperative hospital stay and increases risk of adverse events grade 3 or 4 .

\section{Palliative care}

\section{DOCUMENTING THE JOURNEY FROM DNACPR TO SURGICAL R ZERO - RADICAL EXTENT IN A YOUNG PATIENT WITH METASTATIC UNDIFFERENTIATED LEIOMYOSARCOMA RELAPSE}

SL Smyth*, C Pappa, HJ Jiang, M Abdalla, H Soleymani Majd. Churchill Hospital Gynaecological Oncology, Oxford, UK

\subsection{6/ijgc-2021-ESG0.522}

Introduction/Background* Palliative surgery for advanced cancer involves complex decision-making - to identify ethical dilemmas in consideration of attitudes and factors influencing 